\title{
REVIEW ARTICLE OPEN Wnt signaling pathways in myocardial infarction and the therapeutic effects of Wnt pathway inhibitors
}

\author{
Wen-bin $\mathrm{Fu}^{1}$, Wei Eric Wang ${ }^{1}$ and Chun-yu Zeng ${ }^{1}$
}

Myocardial infarction (MI) is one of the most serious health threats, resulting in huge physical and economic burdens worldwide. Wnt signaling pathways play an important role in developmental processes such as tissue patterning, cell differentiation and cell division. Appropriate regulation of the activities of Wnt signaling pathways is also important for heart development and healing in post-Ml heart. Moreover, Wnt pathway inhibitors have been identified as novel antitumor drugs and applied in ongoing clinical trials. This research progress has generated increasing interests for investigating the effects of Wnt pathway inhibitors on Ml healing. In this short review, we summarize the roles of Wnt signaling pathways in post-MI heart and the therapeutic effects of Wnt pathway inhibitors on $\mathrm{Ml}$, and discuss the underlying mechanisms of Wnt pathway inhibitors in cardiac repairing.

Keywords: Wnt pathway inhibitors; myocardial infarction; cardiac repairing; therapeutic effect

Acta Pharmacologica Sinica (2019) 40:9-12; https://doi.org/10.1038/s41401-018-0060-4

\section{INTRODUCTION}

Myocardial infarction (MI) is one of the leading causes of morbidity and mortality and threatens human health worldwide [1]. In spite of the therapeutic function of drugs such as adrenoceptor blockers, calcium antagonists and renin-angiotensin system inhibitors [2], the progression of $\mathrm{Ml}$ and pathological remodeling are still irreversible. Recent studies agree on the fact that adult mammalian cardiomyocytes are able to regenerate but with a very limited efficacy [3]. This fact evokes further studies to discover novel drug candidates that aim to reduce pathological remodeling and stimulate cardiac regeneration.

Wnt signaling pathways are essential in heart development and active in post-Ml adult heart $[4,5]$. Recent breakthroughs in the studies on the Wnt signaling pathways have revealed new points of intervention that may lead to novel drug targets for small molecular weight compounds. Wht pathway inhibitors are primarily designed for the treatment of tumors and have been approved in clinical trials $[6,7]$. The effect of Wnt pathway inhibitors in the field of cardiac protection has aroused sustained attention towards applying these inhibitors to treat MI [8-10]. In this review, we summarize the regulating mechanisms of Wnt signaling pathways in $\mathrm{Ml}$ and the effects of Wnt pathway inhibitors against Ml.

\section{WNT SIGNALING PATHWAYS AND CARDIOMYOGENESIS}

Wnt was first discovered as Int-1, and then it was found to be a homologous gene of the wingless gene in Drosophila [11]. Wnt signaling pathways include the canonical Wnt/ $\beta$-catenin pathway, non-canonical Wnt/planar cell polarity (PCP) pathway and $\mathrm{Wnt} / \mathrm{Ca}^{2+}$ dependent pathway (Fig. 1) [6]. All three pathways are activated by the binding of a Wnt-protein ligand to a Frizzled family receptor, which conducts signal to the Dishevelled (Dvl) protein inside the cell [12]. The secretion of Wnt proteins is dependent on palmitoylation by Porcupine [13]. Another docking protein family named low-density lipoprotein receptor $(L R P)$ is also found in the Wnt/Frizzled complex [14]. In the canonical Wnt pathway, $\beta$-catenin is phosphorylated and degraded by a destruction complex, including Axin, glycogen synthase kinase $3 \beta(G S K 3 \beta)$, adenomatous polyposis coli (APC), and casein kinase 1a $(C K 1 a)$. Wht stimulation phosphorylates Dvl protein, dissociates $\beta$-catenin and induces the nuclear translocation of $\beta$-catenin, leading to its interaction with TCF/LEF transcription factors and gene transcription [15]. In the Wnt/PCP pathway, Dvl phosphorylation results in RhoA/ROCK and Rac/Jnk/NFAT pathway activation [16]. In the $\mathrm{Wnt} / \mathrm{Ca}^{2+}$ pathway, phospholipase $\mathrm{C}(P L C)$ is activated and induces the accumulation of intracellular $\mathrm{Ca}^{2+}$, leading to the activation of calmodulin-dependent kinase II (CamKII), calcineurin and protein kinase C (PKC) [17].

The mammalian heart is developed from the lateral plate mesoderm, which fuses together to form the heart tube and subsequently organizes the ventricle and atria [18]. Wnt signaling pathways exert bi-directional regulatory effects at different stages of cardiomyogenesis. The Wnt signaling pathway is activated during the formation of the early embryo to the lateral plate mesoderm but is subsequently inhibited to ensure heart development into its proper size [4]. Wnt activation at the gastrulation stage is essential for the maintenance of undifferentiated progenitor cells $[19,20]$, whereas Wnt inhibition at the postgastrula stages promotes cardiomyocyte differentiation [21, 22]. Different Wnt ligands participate in progress of mesoderm induction and later cardiomyocyte differentiation. Wnt-3 and Wnt-8a regulate mesoderm induction through canonical signaling, whereas $W n t-2, W n t-5 a / b$, and $W n t-11$ regulate cardiomyocyte differentiation via non-canonical signaling [23]. Dissociative $\beta$ catenin is the central player of the canonical Wnt pathway, and its

${ }^{1}$ Department of Cardiology, Daping Hospital, Third Military Medical University, Chongqing 400042, China

Correspondence: Wei Eric Wang (weiericwang@163.com)

Received: 9 January 2018 Accepted: 31 May 2018

Published online: 12 July 2018 


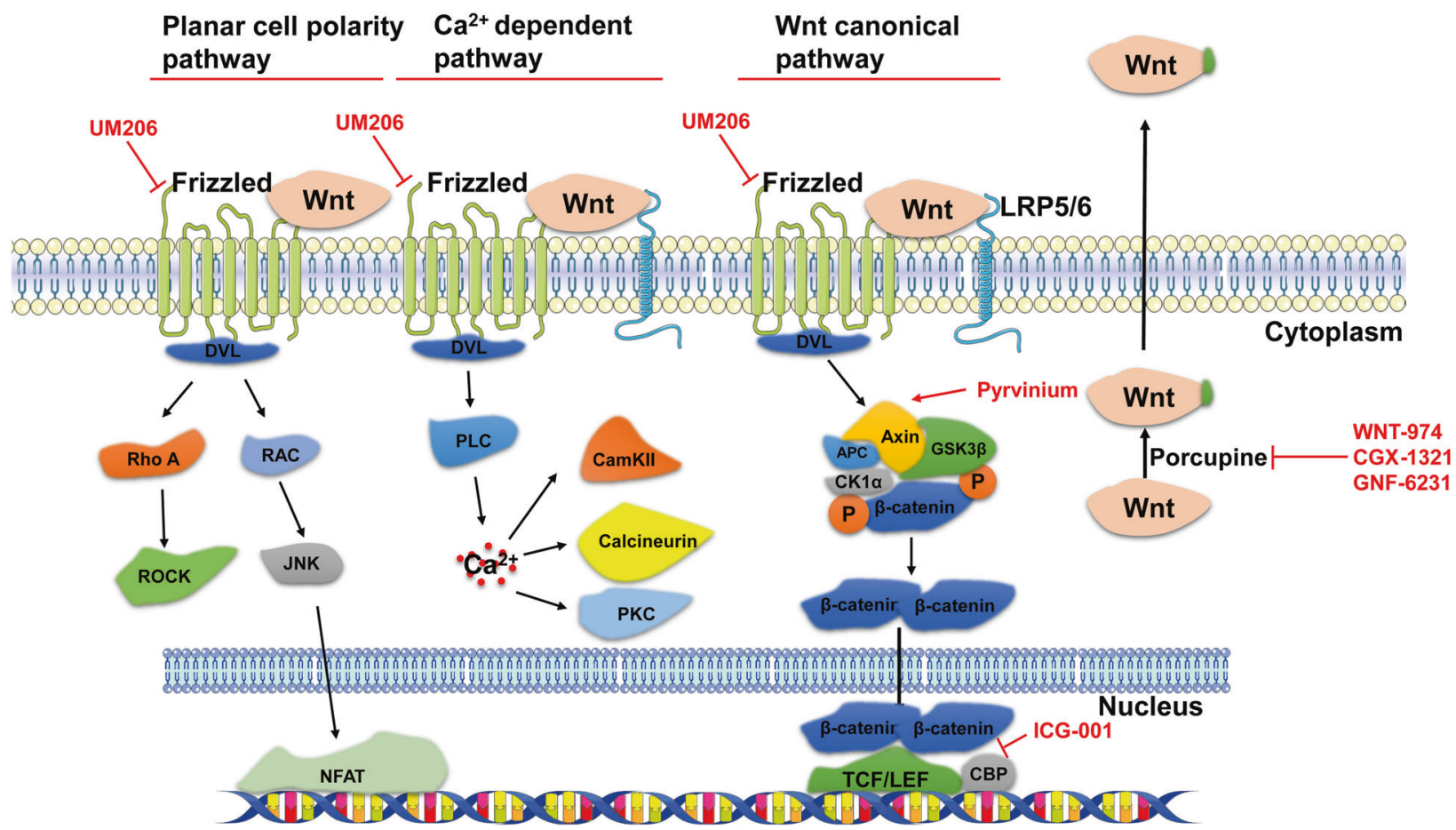

Fig. 1 Wnt signaling pathways and the intervention targets of Wnt pathway inhibitors. The secretion of Wnt proteins is dependent on palmitoylation by Porcupine. Frizzled and low-density lipoprotein receptor (LRP) proteins are membrane receptors for binding Wnt proteins. In the canonical Wnt pathway, Wnt binding leads to $\beta$-catenin nuclear translocation (after dissociation from a complex with Axin, glycogen synthase kinase $3 \beta$ (GSK3 $\beta)$, adenomatous polyposis coli (APC) and casein kinase $1 \alpha(C K 1 \alpha)$ ), causing its interaction with TCF/LEF transcription factors and gene transcription. In the Wnt/PCP pathway, Wnt binding results in RhoA/ROCK and Rac/Jnk/NFAT pathway transduction. In the Wnt/Ca ${ }^{2+}$ pathway, Wnt binding leads to phospholipase $\mathrm{C}$ (PLC) activation and the accumulation of intracellular $\mathrm{Ca}^{2+}$, which then leads to the activation of calmodulin-dependent kinase II (CamKII), calcineurin and protein kinase C (PKC). UM206 targets the Frizzled receptor family; pyrvinium inhibits Axin degradation; ICG-001 inhibits the interaction between $\beta$-catenin and CBP; and WNT-974, CGX-1321 and GNF-6231 are porcupine inhibitors

nuclear accumulation is a hallmark of Wnt signaling activation [6]. The Wnt/ $\beta$-catenin signaling pathway is also crucial in the formation of second heart field derivatives, such as cardiac outflow tract and right ventricle [24, 25]. Moreover, the inhibition of $\beta$-catenin-mediated transcription is linked with atrial and ventricular growth in zebrafish, indicating its role in cardiomyocyte proliferation [26].

\section{WNT SIGNALING PATHWAYS AND MI IN MAMMALIAN HEART} Activation of Wnt signaling pathways after MI

The pathological process of $\mathrm{MI}$ injury includes three major phases: inflammatory reaction, the formation of granulation tissue and fibrosis [27]. The infiltration of inflammatory cells leads to the release of chemokines and cytokines and the recruitment of macrophages. Then, necrotic debris is cleared, and angiogenesis is activated. Finally, myofibroblasts generate collagen to replace the lost cardiomyocytes and provide compensatory contraction function $[28,29]$.

There is increasing evidence showing that Wnt signaling is triggered during the pathological process of $\mathrm{Ml}$ injury. Quantitative analysis for the expression of Wnt proteins has shown strong Wnt-2, Wnt-4, Wnt-10b, and Wnt-11 upregulation 5 days after Ml [30]. Wnt-1 was upregulated from 1 to 14 days after MI, and upregulated Wnt-4 was observed from 7 to 14 days after $\mathrm{MI}$ in a subsequent study [31]. Axin2 and LEF1 are both Wnt target genes and serve as readouts of Wnt signaling intensity. Using a fatemapping technique with the Axin2 promoter and LacZ labeling, Wnt signaling is proved to be activated in cardiomyocytes located at infarct border zone [32]. The intensity of Wnt signaling peaks at 7 days after $\mathrm{Ml}$ and then is gradually attenuated in fibroblasts, endothelial cells, and progenitor cells [32]. Using TopGAL mouse, which expresses the marker $\beta$-gal under the control of TCF/LEF1, increased Wnt signaling activity has been detected 4 days after $\mathrm{Ml}$ [30]. According to the above results, sustained Wnt activation is associated with the pathological phases after Ml, including inflammation, angiogenesis and fibrosis.

Wht signaling pathways and inflammation in MI

The inflammatory reaction is first activated in response to $\mathrm{Ml}$, which aims at removing necrotic debris and healing the infarct but also leads to cardiac remodeling and dysfunction [33]. It has been reported that a subtype of Wnt proteins, Wnt-5a, which is exclusively expressed in cardiomyocytes [8], promotes the release of $I L-1, I L-6$ and $I L-8$ from mononuclear cells, indicating the proinflammatory effect of Wnt signaling [34]. Moreover, SFRPs, which are endogenous Wnt pathway inhibitors, can protect MI injury by modulating the inflammatory response. Better scar formation and cardiac hemodynamic parameters have been demonstrated when bone marrow cells (BMCs) with overexpressed SFRP1 are transplanted into the infarcted border zone by blocking leukocyte activation and cytokine production [35]. Similarly, SFRP5 is able to inhibit inflammatory cytokine and chemokine gene expression in ischemic heart [36]. Furthermore, the deletion of Wnt inhibitory factor 1 (WIF1) leads to more inflammatory monocytes and severe adverse remodeling, whereas cardiomyocyte-specific WIF1 overexpression attenuates monocyte response and improves cardiac function [37]. Increasing evidence has revealed that non-canonical Wnt signaling pathways are most likely involved in inflammatory processes in ischemic heart. Inflammatory cell differentiation and pro-inflammatory cytokine release can be triggered by the noncanonical Wnt signaling pathway via the CamKII /NFAT pathway [38]. In addition, SFRP5 functions to mitigate inflammation through the non-canonical Wnt-5a/JNK signaling pathway [36]. 
Wnt signaling pathways and angiogenesis in MI

Angiogenesis is reflected as newly formed vessels by endothelial cells, which contribute to cardiac repair and functional recovery after MI. A previous study showed that the Wnt signaling pathway was activated in endothelial cells of the infarct area, which were identified by the accumulation of $\beta$-catenin [39]. Conditional overexpression of $\beta$-catenin in endothelial cells shows progressive cardiac dysfunction via ErbB signaling, indicating Wnt inhibition as a therapeutic strategy for heart failure [40]. Indeed, many kinds of negative Wnt regulators have demonstrated a pro-angiogenesis effect in post-MI heart. Genetic overexpression of SFRP1 can increase capillary density in the scar of Ml by inhibiting the accumulation of cytosolic $\beta$-catenin [41]. Dickkopf2 (DKK2), known as an another Wnt inhibitor, can stimulate the angiogenic sprouting of endothelial cells after MI via LRP6/APC activation, but Dickkopf1 (DKK1) has shown a diminished role in regulating angiogenesis [42]. However, it has been reported that NP12, which can stabilize $\beta$-catenin via inhibiting GSK3 $\beta$, is able to promote angiogenesis and improve ventricular function following $\mathrm{MI}$ by activating the Wnt signaling pathway [43]. Moreover, Wnt-1inducible secreted protein-1 (WISP-1), which is a responsive gene of Wnt activation [44], can promote angiogenesis in post-MI heart via regulating histone deacetylase [45].

Wnt signaling pathways and fibrosis in $\mathrm{MI}$

Cardiac fibrosis is a common process in remodeling hearts after $\mathrm{MI}$ that is formed by myofibroblast invasion and collagen secretion [28]. The canonical Wnt/ $\beta$-catenin signaling pathway plays a dominant role in the regulation of cardiac fibrosis following MI. There is evidence showing that the down-regulation of $\beta$-catenin by aldehyde dehydrogenase- $2(\mathrm{ALDH} 2)$ activity leads to reduced cardiac fibrosis, which may be mediated by phosphorylated GSK3 $\beta$, Wnt-1, and WISP-1 [46]. In the meantime, the transfection of miR154 inhibitors can also decrease the expression of $\beta$-catenin and myofibroblast proliferation via directly binding with DKK2 [47]. Furthermore, TGF $\beta$ signaling plays a key role in the differentiation of myofibroblasts and interacts with the Wnt signaling pathway [48]. Wnt-3a can promote myofibroblast differentiation and TGF $\beta$ expression by triggering the canonical Wnt signaling pathway [49]. The Wnt signaling pathway can promote the release of TGF $\beta$ in the $\beta$-catenin-dependent pathway using a mouse model of autoimmune myocarditis [50], and loss of $\beta$-catenin function in cardiac fibroblasts results in improved cardiac function and suppressed interstitial fibroblasts in a mouse model of pressure overload [51]. However, in transgenic mice with specific $\beta$-catenin interruption in cardiac fibroblasts, impaired wound healing and decreased cardiac performance have been observed [31]. Conversely, the interruption of $\beta$-catenin in epicardial cells leads to compromised cardiac function after MI [31]. These discrepant observations may be explained by the complex roles of Wnt signaling pathways in different stages of $\mathrm{Ml}$ and interactions with other pathways.

\section{THE THERAPEUTIC EFFECT OF SMALL MOLECULE WNT PATHWAY INHIBITORS AGAINST MI IN ANIMAL MODELS}

Pyrvinium is a drug approved by the FDA and identified as a Wnt inhibitor by inhibiting Axin degradation and stabilizing $\beta$-catenin, which can increase $\mathrm{Ki}^{+} 7^{+}$cardiomyocytes in the peri-infarct area and alleviate cardiac remodeling in a mouse model of MI [52]. UM206 is a peptide with a high homology to Wnt-3a/5a, and acts as an antagonist for Frizzled proteins to inhibit Wnt signaling pathway transduction. UM206 could reduce infarct size, increase the numbers of capillaries, decrease myofibroblasts in infarct area of post-MI heart, and ultimately suppress the development of heart failure [53]. ICG-001, which specifically inhibits the interaction between $\beta$-catenin and $C B P$ in the Wnt canonical signaling pathway, can promote the differentiation of epicardial progenitors, thereby contributing to myocardial regeneration and improving cardiac function in a rat model of MI [54]. Small molecules invaliding Porcupine have been further studied, such as WNT-974, GNF-6231 and CGX-1321. WNT-974 decreases fibrosis in post-MI heart, with a mechanism of preventing collagen production in cardiomyocytes by blocking secretion of Wnt-3, a profibrotic agonist, from cardiac fibroblasts and its signaling to cardiomyocytes [8]. The phosphorylation of DVL protein is decreased in both the canonical and non-canonical Wnt signaling pathways by WNT-974 administration [8]. GNF-6231 prevents adverse cardiac remodeling in a mouse model of MI by inhibiting the proliferation of interstitial cells, increasing the proliferation of $\mathrm{SCa}^{+}$cardiac progenitors and reducing the apoptosis of cardiomyocytes [9]. Similarly, we demonstrate that CGX-1321, which has also been applied in a phase I clinical trial to treat solid tumors (NCT02675946), inhibits both canonical and non-canonical Wnt signaling pathways in post-MI heart. CGX-1321 promotes cardiac function by reducing fibrosis and stimulating cardiomyocyte proliferation-mediated cardiac regeneration in a Hippo/YAPindependent manner [10]. These reports implicate that Wnt pathway inhibitors are a class of potential drugs for treating MI through complex mechanisms, including reducing cardiomyocyte death, increasing angiogenesis, suppressing fibrosis and stimulating cardiac regeneration.

\section{CONCLUSION}

Both the canonical and non-canonical Wnt signaling pathways are essential for heart development and play an important role in adult heart with $\mathrm{MI}$ injury. The inhibition of Wnt signaling pathways has been demonstrated to be beneficial in Ml via improving cardiac remodeling. These Wnt inhibitory compounds have been proven to be safe in clinical trials and can be potential drugs for treating Ml. However, novel Wnt pathway inhibitors with minimized toxicity and a more exclusive effect on the heart are still needed.

\section{FUNDING}

This project was supported by grants from the National Natural Science Foundation of China (81670277 and 31730043), Innovation Team of the National Natural Science Foundation (81721001) and Program for Changjiang Scholars and Innovative Research Team in University (IRT1216).

\section{ADDITIONAL INFORMATION}

Competing interests: The authors declare that they have no conflict of interest.

\section{REFERENCES}

1. Carney RM, Freedland KE. Depression and coronary heart disease. Nat Rev Cardiol. 2017;14:145-55.

2. Ezekowitz JA, O'Meara E, Mcdonald MA, Abrams H, Chan M, Ducharme A, et al 2017 comprehensive update of the Canadian Cardiovascular Society Guidelines for the management of heart failure. Can J Cardiol. 2017;33:1342-433.

3. Bassat E, Mutlak YE, Genzelinakh A, Shadrin IY, Umansky KB, Yifa O, et al. The extracellular matrix protein agrin promotes heart regeneration in mice. Nature. 2017;547:179-84.

4. Gessert S, Kühl M. The multiple phases and faces of Wnt signaling during cardiac differentiation and development. Circ Res. 2010;107:186-99.

5. Ozhan G, Weidinger G. Wnt/B-catenin signaling in heart regeneration. Cell Regen. 2015;4:3.

6. Duchartre Y, Kim YM, Kahn M. The Wnt signaling pathway in cancer. Crit Rev Oncol Hematol. 2016;99:141-9.

7. Krishnamurthy $\mathrm{N}$, Kurzrock R. Targeting the Wnt/beta-catenin pathway in cancer: Update on effectors and inhibitors. Cancer Treat Rev. 2017:62:50-60.

8. Moon J, Zhou H, Zhang LS, Tan W, Liu Y, Zhang S, et al. Blockade to pathological remodeling of infarcted heart tissue using a porcupine antagonist. Proc Natl Acad Sci U S A. 2017;114:1649-54.

9. Bastakoty D, Saraswati S, Joshi P, Atkinson J, Feoktistov I, Liu J, et al. Temporary, systemic Inhibition of the WNT/ $\beta$-Catenin pathway promotes regenerative cardiac repair following myocardial infarct. Cell Stem Cells Regen Med. 2016; 2. https://www.ncbi.nlm.nih.gov/pubmed/?term $=28042617$ 
10. Yang $D, F u$ W,Li L,Xia X,Liao Q,Yue R, et al. Therapeutic effect of a novel Wnt pathway inhibitor on cardiac regeneration after myocardial infarction. Clin Sci. 2017;131:2919-32.

11. Clevers $\mathrm{H}$. Wnt/beta-catenin signaling in development and disease. Cell. 2006;127:469-80.

12. Schulte G, Bryja V. The Frizzled family of unconventional G-protein-coupled receptors. Trends Pharmacol Sci. 2007;28:518-25.

13. Janda CY, Garcia KC. Wnt acylation and its functional implication in Wnt signalling regulation. Biochem Soc Trans. 2015;43:211-6.

14. Joiner DM, Ke J, Zhong Z, Xu HE, Williams BO. Lrp5 and Lrp6 in development and disease. Trends Endocrinol Metab. 2013;24:31-9.

15. Macdonald BT, Tamai K, He X. Wnt/beta-catenin signaling: components, mechanisms, and diseases. Dev Cell. 2009;17:9-26.

16. Simons $M$, Mlodzik M. Planar cell polarity signaling: from fly development to human disease. Annu Rev Genet. 2008:42:517-40.

17. Kühl M, Sheldahl LC, Park M, Miller JR, Moon RT. The Wnt/Ca ${ }^{2+}$ pathway: a new vertebrate Wnt signaling pathway takes shape. Trends Genet Tig. 2000;16:279-83.

18. Brade T, Männer J, Kühl M. The role of Wnt signalling in cardiac development and tissue remodelling in the mature heart. Cardiovasc Res. 2006;72:198-209.

19. Lindsley RC, Gill JG, Kyba M, Murphy TL, Murphy KM. Canonical Wnt signaling is required for development of embryonic stem cell-derived mesoderm. Development. 2006;133:3787-96.

20. Bakre MM, Hoi A, Mong JC, Koh YY, Wong KY, Stanton LW. Generation of multipotential mesendodermal progenitors from mouse embryonic stem cells via sustained Wnt pathway activation. J Biol Chem. 2007;282:31703-12.

21. Ueno $S$, Weidinger $G$, Osugi $T$, Kohn AD, Golob JL, Pabon $L$, et al. Biphasic role for Wnt/beta-catenin signaling in cardiac specification in zebrafish and embryonic stem cells. Proc Natl Acad Sci USA 2007;104:9685-90.

22. Tzahor $E$, Lassar AB. Wnt signals from the neural tube block ectopic cardiogenesis. Gene Dev. 2001;15:255-60.

23. Mazzotta S, Neves C, Bonner RJ, Bernardo AS, Docherty K, Hoppler S. Distinctive roles of canonical and noncanonical Wnt signaling in human embryonic cardiomyocyte development. Stem Cell Rep. 2016;7:764-76.

24. Ai D, Fu X, Wang J, Lu MF, Chen L, Baldini A, et al. Canonical Wnt signaling functions in second heart field to promote right ventricular growth. Proc Natl Acad Sci U S A. 2007;104:9319-24.

25. Furtado MB, Wilmanns JC, Chandran A, Perera J, Hon O, Biben $C$, et al. Point mutations in murine Nkx2-5 phenocopy human congenital heart disease and induce pathogenic Wnt signaling. JCI Insight. 2017;2:e88271.

26. Ni TT, Rellinger EJ, Mukherjee A, Xie S, Stephens L, Thorne CA, et al. Discovering small molecules that promote cardiomyocyte generation by modulating Wnt signaling. Chem Biol. 2011;18:1658-68.

27. Cleutjens JPM, Blankesteijn WM, Daemen MJAP, Smits JFM. The infarcted myocardium: simply dead tissue, or a lively target for therapeutic interventions. Cardiovasc Res. 1999;44:232-41.

28. Borne SWMVD, Diez J, Blankesteijn WM, Verjans J, Hofstra L, Narula J. Myocardial remodeling after infarction: the role of myofibroblasts. Nat Rev Cardiol. 2010;7:30-7.

29. Daskalopoulos EP, Janssen BJ, Blankesteijn WM. Myofibroblasts in the infarct area: concepts and challenges. Microsc Microanal. 2012;18:35-49.

30. Aisagbonhi O, Rai M, Ryzhov S, Atria N, Feoktistov I, Hatzopoulos AK. Experimental myocardial infarction triggers canonical Wnt signaling and endothelial-tomesenchymal transition. Dis Models Mech. 2011;4:469-83.

31. Duan J, Gherghe C, Liu D, Hamlett E, Srikantha L, Rodgers L, et al. Wnt1/ßcatenin injury response activates the epicardium and cardiac fibroblasts to promote cardiac repair. EMBO J. 2012;31:429-42.

32. Oerlemans MIFJ, Goumans MJ, Middelaar BV, Clevers H, Doevendans PA, Sluijter JPG. Active Wnt signaling in response to cardiac injury. Basic Res Cardiol. 2010;105:631-41.

33. Frangogiannis NG. The inflammatory response in myocardial injury, repair and remodeling. Nat Rev Cardiol. 2014;11:255-65.

34. Blumenthal A, Ehlers S, Lauber J, Buer J, Lange C, Goldmann T, et al. The Wingless homolog WNT5A and its receptor Frizzled-5 regulate inflammatory responses of human mononuclear cells induced by microbial stimulation. Blood. 2006; 108:965-73.

35. Barandon L, Casassus F, Leroux L, Moreau C, Allières C, Lamazière JM, et al. Secreted frizzled-related protein-1 improves postinfarction scar formation through a modulation of inflammatory response. Arterioscler Thromb Vasc Biol. 2011;31:e80-7.

36. Nakamura K, Sano S, Fuster JJ, Kikuchi R, Shimizu I, Ohshima K, et al. Secreted frizzled-related protein 5 diminishes cardiac inflammation and protects the heart from ischemia/reperfusion injury. J Biol Chem. 2016;291:2566-75.

37. Meyer IS, Jungmann A, Dieterich C, Zhang M, Lasitschka F, Werkmeister S, et al. The cardiac microenvironment uses non-canonical WNT signaling to activate monocytes after myocardial infarction. EMBO Mol Med. 2017:9:1279-93.
38. Pereira C, Schaer DJ, Bachli EB, Kurrer MO, Schoedon G. Wnt5A/CaMKII signaling contributes to the inflammatory response of macrophages and is a target for the antiinflammatory action of activated protein $C$ and interleukin-10. Arterioscler Thromb Vasc Biol. 2008;28:504-10.

39. Blankesteijn WM, van Gijn ME, Essers-Janssen YP, Daemen MJ, Smits JF. Betacatenin, an inducer of uncontrolled cell proliferation and migration in malignancies, is localized in the cytoplasm of vascular endothelium during neovascularization after myocardial infarction. Am J Pathol. 2000;157:877-83.

40. Nakagawa A, Naito AT, Sumida T, Nomura S, Shibamoto M, Higo T, et al. Activation of endothelial $\beta$-catenin signaling induces heart failure. Sci Rep. 2016;6:25009.

41. Barandon L, Couffinhal T, Ezan J, Dufourcq P, Costet P, Alzieu P, et al. Reduction of infarct size and prevention of cardiac rupture in transgenic mice overexpressing FrzA. Circulation. 2003;108:2282-9.

42. Min JK, Park H, Choi HJ, Kim Y, Pyun BJ, Agrawal V, et al. The WNT antagonist Dickkopf2 promotes angiogenesis in rodent and human endothelial cells. J Clin Invest. 2011;121:1882-93.

43. Baruah J, Hitzman R, Zhang J, Chaudhuri S, Mastej V, Wary KK. The allosteric glycogen synthase kinase-3 inhibitor NP12 limits myocardial remodeling and promotes angiogenesis in an acute myocardial infarction model. J Biol Chem. 2017;292:20785-98.

44. Mill C, Monk BA, Williams $H$, Simmonds SJ, Jeremy JY, Johnson JL, et al. Wnt5ainduced Wnt1-inducible secreted protein-1 suppresses vascular smooth muscle cell apoptosis induced by oxidative stress. Arterioscler Thromb Vasc Biol. 2014;34:2449-56.

45. Wright LH, Herr DJ, Brown SS, Kasiganesan $H$, Menick DR. Angiokine Wisp-1 is increased in myocardial infarction and regulates cardiac endothelial signaling. $\mathrm{JCl}$ Insight. 2018;3:95824.

46. Zhao X, Hua $Y$, Chen $H$, Yang $H$, Zhang $T$, Huang $G$, et al. Aldehyde dehydrogenase- 2 protects against myocardial infarction-related cardiac fibrosis through modulation of the Wnt/ $\beta$-catenin signaling pathway. Ther Clin Risk Manag. 2015;11:1371-81.

47. Sun LY, Bie ZD, Zhang CH, Li H, Li LD, Yang J. MiR-154 directly suppresses DKK2 to activate Wnt signaling pathway and enhance activation of cardiac fibroblasts. Cell Biol Int. 2016;40:1271-9.

48. Hermans KCM, Daskalopoulos EP, Blankesteijn WM. The Janus face of myofibroblasts in the remodeling heart. J Mol Cell Cardiol. 2016;91:35-41.

49. Carthy JM, Garmaroudi FS, Luo Z, McManus BM. Wnt3a induces myofibroblast differentiation by upregulating tgf- $\beta$ signaling through smad 2 in a $\beta$-catenindependent manner. PLoS One. 2011;6:e19809.

50. Blyszczuk P, Müller-Edenborn B, Valenta T, Osto $E$, Stellato $M$, Behnke $S$, et al. Transforming growth factor- $\beta$-dependent Wnt secretion controls myofibroblast formation and myocardial fibrosis progression in experimental autoimmune myocarditis. Eur Heart J. 2017;38:1413-25.

51. Xiang $F L$, Fang M, Yutzey KE. Loss of $\beta$-catenin in resident cardiac fibroblasts attenuates fibrosis induced by pressure overload in mice. Nat Commun. 2017;8:712.

52. Saraswati S, Alfaro MP, Thorne CA, Atkinson J, Lee E, Young PP. Pyrvinium, a potent small molecule Wnt inhibitor, promotes wound repair and post-mi cardiac remodeling. PLoS One. 2010;5:e15521.

53. Laeremans $H$, Hackeng $T M$, van Zandvoort MA, Thijssen VL, Janssen BJ, Ottenheijm $\mathrm{HC}$, et al. Blocking of frizzled signaling with a homologous peptide fragment of wnt3a/wnt5a reduces infarct expansion and prevents the development of heart failure after myocardial infarction. Circulation. 2011;124:1626-35.

54. Sasaki $T$, Hwang $H$, Nguyen $C$, Kloner RA, Kahn M. The small molecule Wnt signaling modulator ICG-001 improves contractile function in chronically infarcted rat myocardium. PLoS One. 2013;8:e75010.

Open Access This article is licensed under a Creative Commons Attribution 4.0 International License, which permits use, sharing, adaptation, distribution and reproduction in any medium or format, as long as you give appropriate credit to the original author(s) and the source, provide a link to the Creative Commons license, and indicate if changes were made. The images or other third party material in this article are included in the article's Creative Commons license, unless indicated otherwise in a credit line to the material. If material is not included in the article's Creative Commons license and your intended use is not permitted by statutory regulation or exceeds the permitted use, you will need to obtain permission directly from the copyright holder. To view a copy of this license, visit http://creativecommons. org/licenses/by/4.0/.

(c) The Author(s) 2018 